\title{
Analysis of factors which contribute to inter-enterprise competition
}

\author{
Takumi Shimizu \\ Yusuke Takada \\ Takashi Iba \\ Faculty of Policy Management, Keio University
}

\begin{abstract}
In this paper, we replicate Nelson-Winter model in order to analyze the inter-enterprise competition from the perspective of economic change. For this purpose, we build the simulation model as MultiAgent-Based Simulation in PlatBox Simulator. By replicating the Nelson-Winter model, which clarifies the mechanism of competition among firms, further studies on economic growth can be made. As a result dynamic changes of economy is caused by competition among firms as they change their routine through technology innovation.
\end{abstract}

Keywords: Evolutionary Economics, Computer Simulation, Nelson-Winter Model

\section{Introduction}

How analyze economic and social change? This issue is one of the matters of concern to the entire world. At the present day, the impact of firms is growing daily. It is very important for us to understand more about inter-enterprise competition from the perspective of economic change.

This research has two fundamental features. One is a conceptual feature: "Perspective of evolution". And the other one is a technical feature: "Multi-Agent-Based Simulation". A new type of economic analysis can be achieved beyond the limit of neoclassical economics by using this method.

\section{Background}

To grasp the changes in economic field, this research will be focusing on firm's changes of the routine and technology. The target will be the routine of the organization, because the routine cannot be reduced to a person. This way, a new approach to grasp economic changes can be taken.

A significance of this research is the replication of "Nelson-Winter model" with high degree of freedom of experiment and high possibility of expansion. By replicating this acknowledged evolutionary economics model on PlatBox Simulator [4] enabling to experiment repeatedly by easily changing the parameter setting and to build models including the subject with the concept of complex systems. By replicating Nelson-Winter model on PlatBox Simulator, this paper gives us a chance to rethink the past achievements of evolutionary economics and to search for new possibilities of expansion.

There are two characteristics in this paper. One is the fact that this paper goes through not only the existent economic and business management analysis but also uses computer simulation for analyzing economic changes. The other is that the both result of the simulation and existent branch of knowledge is referred to increase and explain the validity of the model and its logic.

\section{Model}

Nelson-Winter model is a model dealing with "evolution of producing technology" when each company is producing a same product in a specific industry. The term "Evolution of producing technology" means to increase the productivity by either developing a necessary technology within the company or copying other companies' developed technologies. This increases the productivity of the whole industry and this is how industry evolves.

\subsection{Conceptual Modeling}

This model is structured by three agents: "Firm" which produces and develops technologies, "Market" which tallies corporate activities, and "Bank" which finances to companies (Figure 1). Market and Company/ Bank are related through "Market Relation". Company and Bank are related through "Finance Relation". The summary of Behavior each agent holds is as listed below.

In the perspective of Behavior, Firm agent has "Producing Behavior" to produces goods, and 


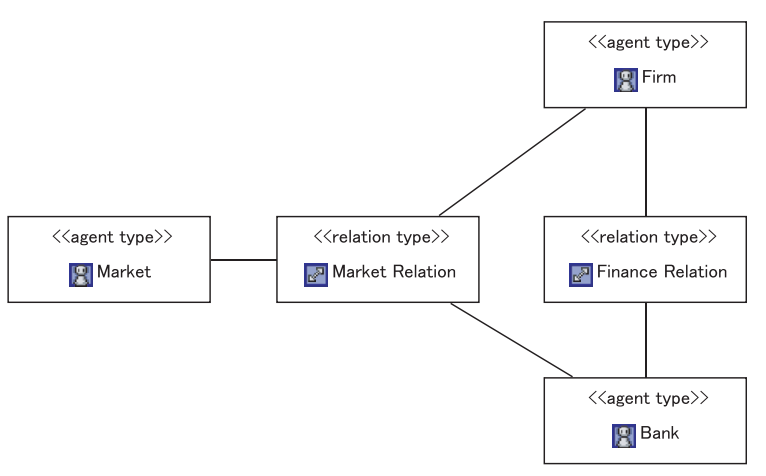

Figure 1: Class Diagram of Agent and Relation
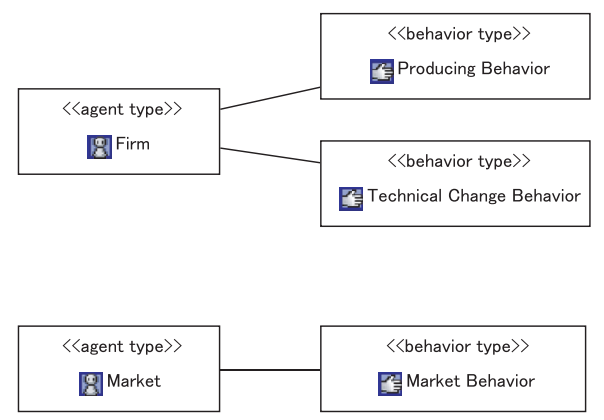

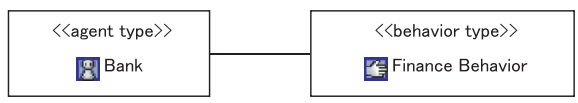

Figure 2: Class Diagram of Agent and Behavior

"Technical change Behavior" to make investments to new technology (Figure 2). Market agent has "Market Behavior" to grasp the whole corporate activities and decide the most appropriate price and producing technology. Bank agent has "Finance Behavior" to finance based on each firm's income ratio and market share.

\subsection{Simulation Modeling}

\subsubsection{Behavior of Firm}

Produce the goods: Each firm calculates the amount of goods it produces in time $t$. The output $Q_{i_{t}}$ is determined by the productivity $A_{i_{t}}$ and the capital stock $K_{i_{t}}$.

$$
Q_{i_{t}}=A_{i_{t}} K_{i_{t}}
$$

Invest in new technology: Each firm develops new technology in order to boost their productivity, and it tries to imitate a firm which has the top production technologies at the same time. Investment for innovation $R_{i_{t}}^{n}$ is determined by the ratio of innovation $r^{n}$ and capital stock $K_{i_{t}}$.

$$
R_{i_{t}}^{n}=r^{n} K_{i_{t}}
$$

Investment of imitation $R_{i_{t}}^{m}$ is determined by the ratio of imitation $r^{m}$ and the capital stock $K_{i_{t}}$.

$$
R_{i_{t}}^{m}=r^{m} K_{i_{t}}
$$

Adoption judgment: Firm makes a decision on whether it is able to acquire new technology or not after it invested in new technology development. The success of the investment is determined by two factors, one is parameters of probability which is already set, and the other is "amount of investment".

Probability of success $\gamma_{i_{+}}^{n}$ is determined by the probability of innovation $d^{n}$ and investment for innovation $R_{i_{t}}^{n}$.

$$
\gamma_{i_{t}}^{n}=d^{n} R_{i_{t}}^{n}
$$

Probability of success $\gamma_{i_{t}}^{m}$ is determined by probability of imitation $d^{m}$ and investment of imitation $R_{i_{t}}^{m}$.

$$
\gamma_{i_{t}}^{m}=d^{m} R_{i_{t}}^{m}
$$

Comparing "a probability of success" which is calculated in this action with "judgment standards", Firm acquires new technology only in the case of "probability of success" has a higher value than "judgment standards".

Select the technology: Firm selects the top technology from all availabilities after finishing a series of investments.

Calculate profit: Firm calculates profit in $t$-th period. The net income $Z_{i_{t}}$ is calculated by the sales $S_{i_{t}}$, production cost $C_{i_{t}}$, investment of innovation $R_{i_{t}}^{m}$, and investment of imitation $R_{i_{t}}^{n}$.

$$
Z_{i_{t}}=S_{i_{t}}-\left(C_{i_{t}}+R_{i_{t}}^{m}+R_{i_{t}}^{n}\right)
$$

Get finance for Bank/ Update capital stock: Based on the profit calculated above, Bank is able to finance Firm. The capital stock for the next term $K_{i, t+1}$ is determined by the outcome of the following equation, the diminution rate multiplies by the capital stock combined with the profit and the financing $I_{i_{t}}$.

$$
K_{i, t+1}=I_{i_{t}}+(1-\delta) K_{i_{t}}
$$




\subsubsection{Behavior of Market}

Calculate total market output: Market tallies the amount of production of each firm in $t$-th period $Q_{i_{t}}$, and calculates total market output $Q_{t}$.

$$
Q_{t}=\sum_{i} Q_{i_{t}}
$$

Decide the best technology: Market decides the best production technology by comparing "Productivity" of each firm. The "Best technology" which is determined by this action will be the one for firm to be borrowed.

Calculate the Price: The price of each product $P_{t}$ is determined by putting "Market output" $Q_{t}$ which is calculated above into Price function. Each Firm calculates the sales in this period by getting information on "Price" from Market.

$$
P_{t}=D\left(Q_{t}\right)
$$

\subsubsection{Behavior of Bank}

Limitation of finance: Bank determines the limitation of amount financed $I_{i_{t}} \max$ based on the profit ratio and Financial ratio of each firm $G\left(\pi_{i_{t}}, b\right)$.

$$
I_{i_{t}} \max =G\left(\pi_{i_{t}}, b\right) K_{i_{t}}
$$

Appropriate amount financed: Bank determines appropriate financing sum based on Market share, markup ratio and diminution ratio of each firm. Appropriate amount financed $I_{i_{t}}$ des is determined by Market share $\rho_{i_{t}}$, markup ratio $\mu_{i_{t}}$, diminution ratio $\delta$, and capital stock $K_{i_{t}}$.

$$
I_{i_{t}} d e s=H\left(\rho_{i_{t}}, \mu_{i_{t}}, \delta\right) K_{i_{t}}
$$

Decide the actual loan amount: Bank selects the lower financing sum by comparing those two listed above. Then, it is compared with 0 , and the higher will be the actual financing sum.

$$
I_{i_{t}}=\max \left[0,\left[I_{i_{t}} \text { des }, I_{i_{t}} \max \right]\right]
$$

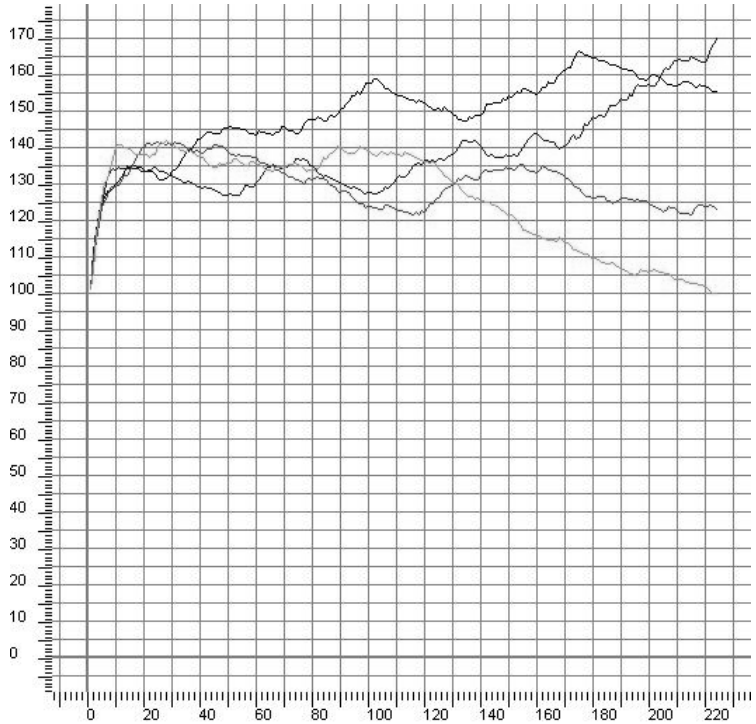

Figure 3: Transition in capital stock of each firm (200 steps)

\section{Simulation Experiments and Results}

The default setting of the agent is as follow:

- Number of Firm $=4$

- Productivity $=0.1$

- Capital stock $=89.7$

- Number of Market = 1

- Number of Bank = 1

- Financial ratio $=1.0$

Analysis of this experiment will be carried out by using graphs of productivity transition and capital stock states of four Companies. Though this model is capable of having many other parameters, this research focuses on the default setting from "Evolutionary Economics" (1994, Andersen).

Figure 3 shows the transition of capital stock, which passed over 200 steps, in short, this industry is early stage of growth. At first, one firm innovates new technologies. Then other firms imitate its best practice or also realize new technological innovations. The productivity of industry as a whole is growing rapidly. However, the difference between two firms which are on the winning side and other two firms which are on the losing group becomes increasingly prominent.

Next, it is of value to watch changes in the industrial structure in mature phase. Figure 4 which passed over 900 steps shows that this industry enter its maturity. Second runner-up is also going into a decline around 400 steps over. This market 


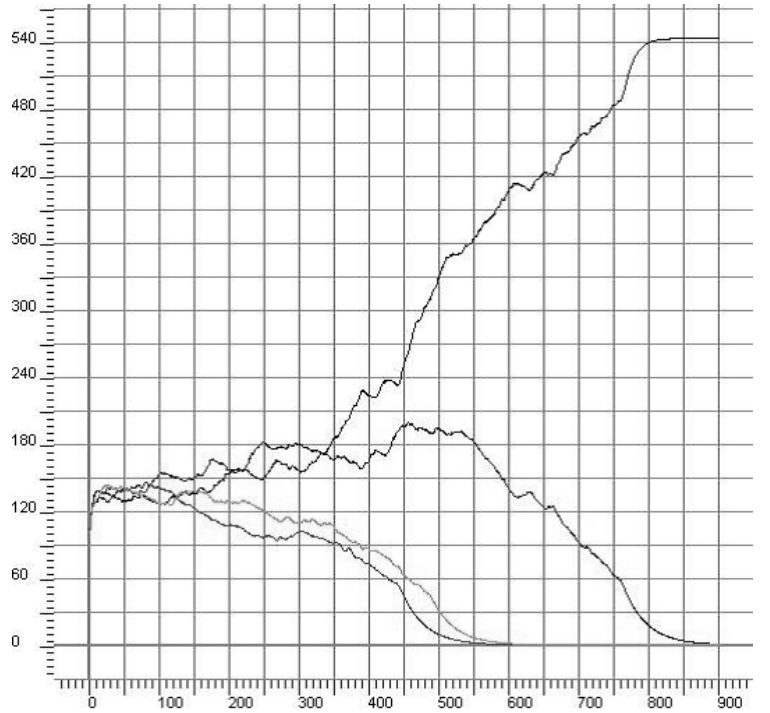

Figure 4: Transition in capital stock of each firm (900 steps)

becomes Winner-Take-All Market. Leading company, however, result in less innovation after 800 steps.

This simulation model can be easily changed internal parameters. In order to analyze an industry which makes innovation at a sluggish pace, innovation mechanism should be changed. Please refer to Figure 5. This chart doesn't show a phenomena of Winner-Take-All. If evolution of technology is more slowly, suvival rate of firms is higher.

As described above, this simulation shows the process that indicates a higher concentration of capital and generates industrial monopoly. In addition, evolution of industry stops by extinct competition. We can demonstrate the effectiveness and impact of Multi-Agent-Based Simulation and Nelson-Winter model which contains a perspective of evolution.

\section{Conclusion}

In this paper, simulation was taken as an approach to understand economic change using NelsonWinter model. Some kinds of industrial aspects stand out in relief through above-described experiments.

Since this simulation model is made to be an extensible model, as a next phase, this simulation model needs a liquidity, such as "entry and bankruptcy" and "dynamic change of behavior" within the market. By adding these extensions, we can deal with economy and industrial evolution more realistically. The analysis of this model will be continued from various angles.

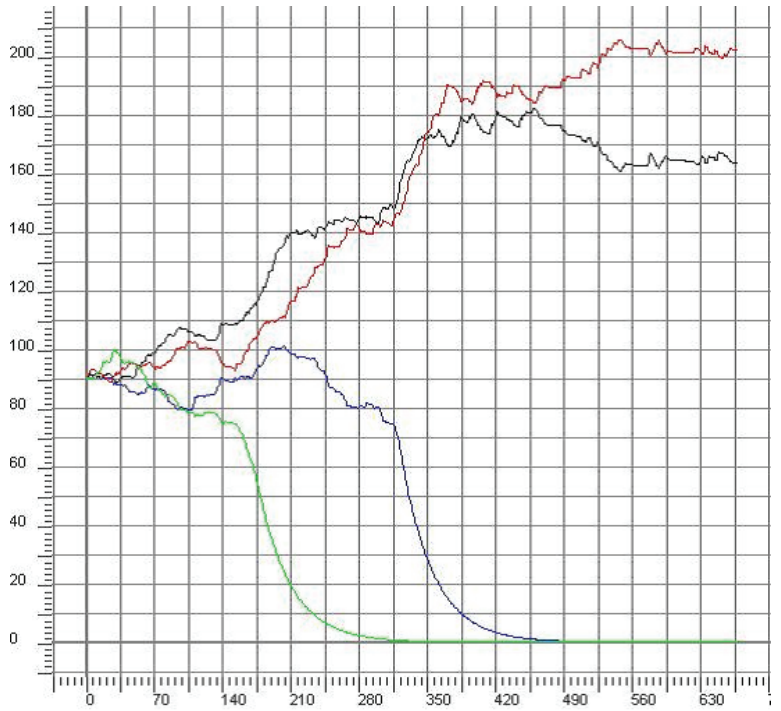

Figure 5: Transition in capital stock of each firm (650 steps: changed parameters)

\section{References}

[1] Andersen, E. S., Jensen, A. K., Madsen, L., and Jorgensen, M.: The Nelson and Winter Models Revisited: Prototypes for ComputerBased Reconstruction of Schumpeterian Competition. http://www.business.aau.dk/ evolution/evoleco/ (1996)

[2] Andersen, E. S.: "Evolutionary Economics: Post-Schumpeterian Contributions". The Continuum International Publishing Group, London/ New York (1994)

[3] Iba, Takashi: A Framework and Tools for Modeling and Simulating Societies as Evolutionary Complex Systems. 2nd. International Conference of the European Social Simulation Association. (2004)

[4] Iba, Takashi: Understanding Social Complex Systems with PlatBox Simulator. The 5th International Conference on Computational Intelligence in Economics and Finance. (2006)

[5] Nelson, Richard R. and Winter, Sidney G.: Evolutionary Theorizing in Economics. Journal of Economic Perspectives. volume 16, number 2, Pages 23-46. (2002)

[6] Nelson, Richard, R and Sidney G. Winter: "An Evolutionary Theory of Economic Change". The Belknap Press of Harvard University Press, Cambridge (1982)

[7] Zhang, Junfu: Growing Silicon Valley on a landscape: an agent-based approach to hightech industrial clusters. Journal of Evolutionary Economics. volume 13, number 5, Pages 529-548. (2003) 